\title{
Measuring the Cultural Evolution and the Modernism of Chinese Farmers of Singapore : An Experiment in the Use of Gamma Measure and of the Guttman Scale
}

\section{Rodolphe De Koninck}

Volume 16, numéro 38, 1972

URI : https://id.erudit.org/iderudit/021055ar

DOI : https://doi.org/10.7202/021055ar

Aller au sommaire du numéro

Éditeur(s)

Département de géographie de l'Université Laval

ISSN

0007-9766 (imprimé)

1708-8968 (numérique)

Découvrir la revue

Citer cet article

De Koninck, R. (1972). Measuring the Cultural Evolution and the Modernism of Chinese Farmers of Singapore : An Experiment in the Use of Gamma Measure and of the Guttman Scale. Cahiers de géographie du Québec, 16(38), 243-262. https://doi.org/10.7202/021055ar

\section{Résumé de l'article}

Au cours d'une étude portant sur la population des agriculteurs chinois de Singapour, une enquête par échantillonnage fut effectuée auprès de 209 foyers d'agriculteurs. À l'analyse du comportement de cette population, trois attributs se dégagèrent, à savoir l'appartenance à un groupe dialectal (Hokkien, Téochiou, Hakka, Cantonais), le type de ferme (élevage, cultures, exploitation mixte) et l'appartenance à l'une des 8 unités régionales. Il était donc nécessaire d'obtenir une mesure comparative des degrés de relation pouvant exister entre ces attributs dominants et d'autres variables. Cependant, l'utilisation d'une mesure discriminatoire s'avéra d'autant plus complexe que les 3 principaux attributs sont étroitement reliés, ce qui est illustré par le haut degré d'association spatiale entre groupe dialectal et type de ferme. De plus, l'utilisation de diverses mesures de corrélation était rendue difficile par la présence de variables nominales et ordinales, par le grand nombre de fréquences inférieures à 5 , ce qui limite la valeur du chi ${ }^{2}$, etc. Finalement une version adaptée de la mesure gamma a permis de dégager des degrés comparatifs de relation entre les 3 principaux attributs et les autres caractéristiques socio-économiques.

Ce résultat méthodologique a d'autant plus de valeur qu'il a permis de dégager une conclusion fondamentale. Alors que, par le passé, le groupe dialectal fut probablement la forme originale d'identité de groupe, il est aujourd'hui supplanté par des formes plus locales et plus spécifiques à Singapour, à savoir le groupe professionnel et surtout la région. En d'autres mots, au sein d'une communauté Chinoise du Nanyang, présumé-ment à Singapour l'une des plus susceptibles de conserver des traces profondes de son héritage culturel, des attributs Singapouriens et même des attributs relevant de régions Singapouriennes semblent représenter le meilleur indicateur socio-économique.

Cette distinction essentielle est même affinée par le recours à une échelle de Guttman servant à mesurer le modernisme des foyers d'agriculteurs. D'après les résultats, alors que les éleveurs semblent de toute évidence les plus modernes, les maraîchers seraient plus modernes que ceux qui combinent cultures et élevage. Mais ce qui est encore plus important dans le " contexte " de plus en plus planifié de Singapour, c'est que les fermes des foyers partiellement agricoles semblent aussi modernes que celles des foyers vivant exclusivement de l'agriculture.
Ce document est protégé par la loi sur le droit d'auteur. L’utilisation des services d'Érudit (y compris la reproduction) est assujettie à sa politique d'utilisation que vous pouvez consulter en ligne.

https://apropos.erudit.org/fr/usagers/politique-dutilisation/ 


\title{
MEASURING THE CULTURAL EVOLUTION AND THE MODERNISM OF CHINESE FARMERS OF SINGAPORE An Experiment in the Use of Gamma Measure and of the Guttman Scale *
}

\author{
by \\ Rodolphe DE KONINCK \\ Département de géographie, université Laval, Québec
}

The problem

As part of a major study on the Chinese farming population of Singapore ${ }^{1}$ a grid sample survey (based on land use data) of 209 farming households was carried out. One of the aims of this survey was to provide means to analyse the behavior of the Chinese farmers. Through the analysis of the answers provided by the 209 recipient heads of households, some dominant variables began to emerge. Most of the isolated socio-economic characteristics showed high correlations when computed against the dialect group variable; the same occured however when they were correlated with the type of farm variable as well as with the regional location one. There naturally arose the question of which of these three dominant attributes was the most reliable, the most discriminatory indicator. Before we detail the nature of the problem and the methods tested to solve if, it appears necessary to give at this stage a few indications concerning the nature of these three attributes.

\section{The dialect groups}

Each respondant belonged to one of four different dialect groups, namely, by order of importance, the Hokkien, the Teochew, the Hakka and Cantonese groups. These are the most important but not the only Chinese dialect groups to be found in Singapore. Some of the others, such as the Hainanese, have a few representatives in the rural areas but none were

" Acknowledgements. This ṕaper is based essentially on a chapter of a Ph.D. thesis previously referred to and presented in 1970 at the University of Singapore. In the handling and analysis of the data contained in this chapter, I benefited greatly from the help and advice of Dr Peter Weldon of the Sociology Department, and of Dr David Gibbons (now at the University of Penang) of the Political Science Department. Any error or discrepancy contained in this paper is naturally my sole responsability.

1 Unpublished Ph.D. thesis presented at the University of Singapore in 1970, and entitled Chinese Farmers of Singapore : a study in social geography. 


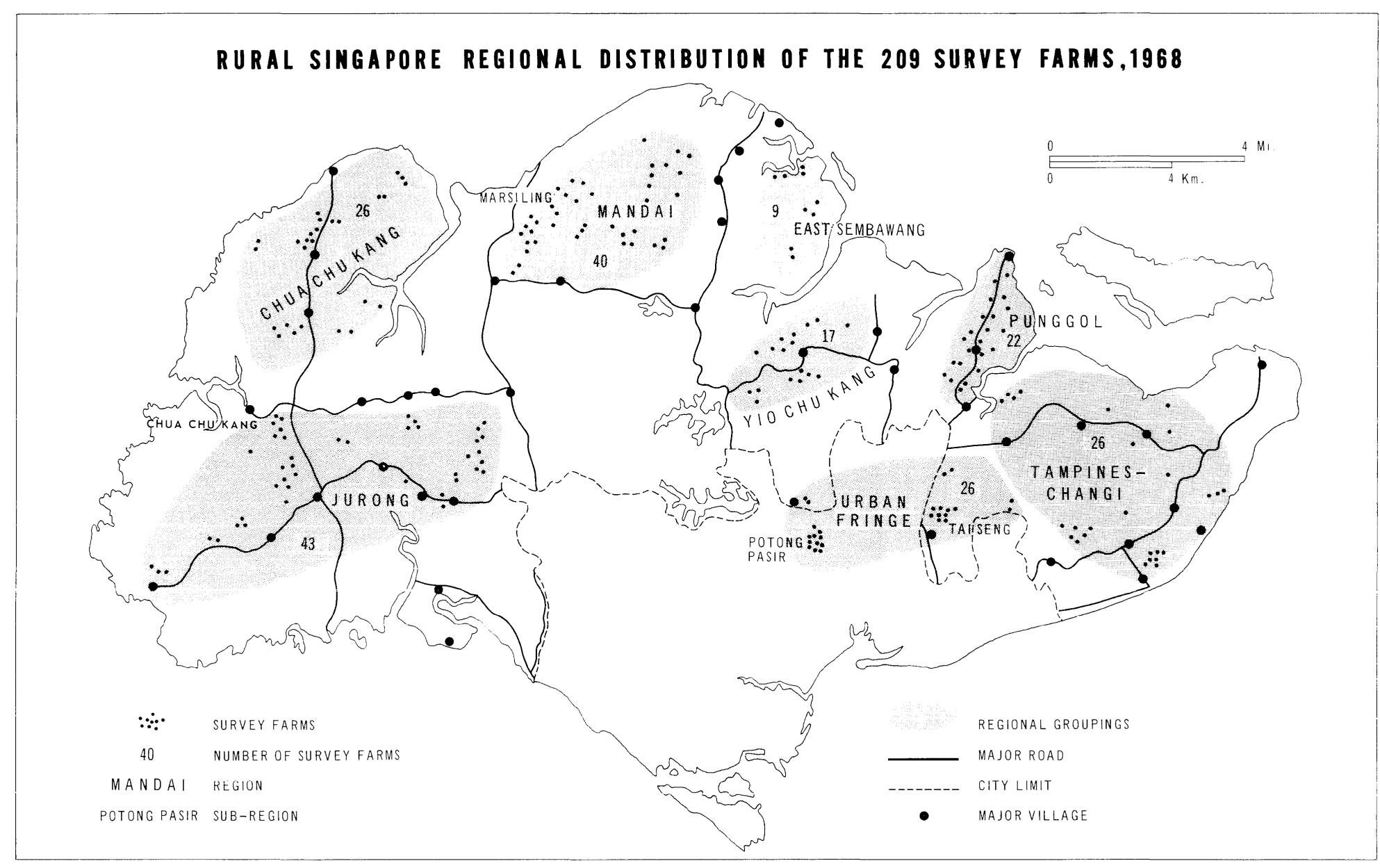


encountered in this survey. There is nothing surprising however in this since representatives of dialect groups do tend to concentrate spatially and professionnally (Neville, 1966). Thus, some dialect groups are very rarely represented in the rural farm sector. That the allegiance to a dialect group is of importance does not have to be demonstrated in this paper; the simple fact that it emerged as a dominant distinguishing attribute explains our reference to it.

\section{The farm types}

On individual plots averaging 2.2 acres in size, the Chinese smallholders produce, essentially for the city, a great variety of goods ranging from the products of pig, poultry, fish and crocodile farms to vegetables, fruits, tobacco and flowers. The most important productions are pigs, chickens, eggs, vegetables and fruits. As a result, three very distinct types of farms are to be found: those that produce solely livestock goods, those who specialize on crops and finally the farms that combine both, the mixed farms.

\section{The regions}

These farms are spread out in a discontinuous belt surrounding and sometimes intermingling with the urban area. A major feature in the distribution of farm land in rural Singapore is the existence of numerous " pockets » of farms, a fact often linked with the presence of alluvial flats. Another important feature however is that these pockets are in turn either centered on major roads (ex: Punggol) or surrounded by a network of them (ex : Mandai). These roads themselves follow broad features of the landscape and generally make their way through the low rollings hills so characteristic of rural Singapore (Wong, 1969). Often ending up at the water's edge their pattern underlines the partitioning of rural Singapore into regional units dependent on these roads on which the servicing villages are to be found (figure 1). In fact eight such units had been defined prior to the survey and had provided the first elements in the construction of the grid to be relied on for the sample. Based both on natural and on man-made features (including administrative ones), these eight units can be regrouped into four larger regions. While all statistical computing was carried out on the basis of the breakdown into eight units, reference is often made to broader regions. Designated according to cardinal points these nevertheless correspond to actual regional units defined topographically (De Koninck, 1970, pp. 56-71).

The regions àre then : Jurong and Chua Chu Kang in the West; Mandai in the North; East Sembawang, Yio Chu Kang and Punggol in the Northeast and Tampines Changi and the "Urban Fringe " units in the East (table 1).

As stated, each of the 3 major attributes, taken independently, discriminates with efficiency between various other attributes such as length of establishment, size of household, size of farm, type of tenure (figure 2). 


\section{LAND TENURE CATEGORY BY DIALECT GROUPS, BY FARM TYPES AND BY REGIONS}

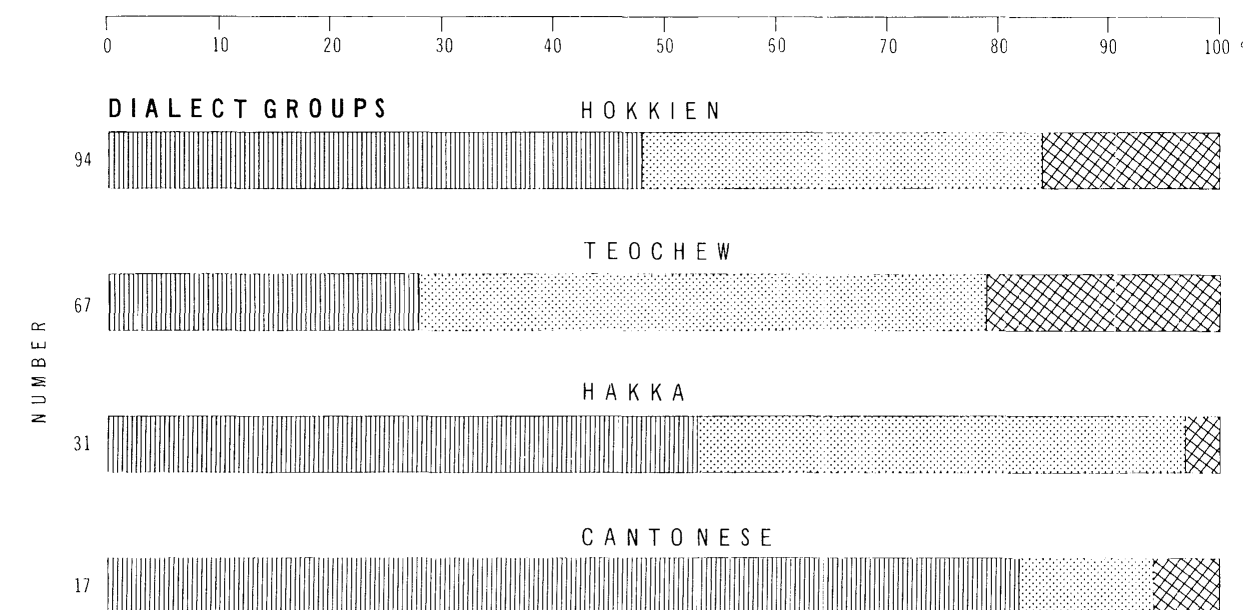

TOTAL 209
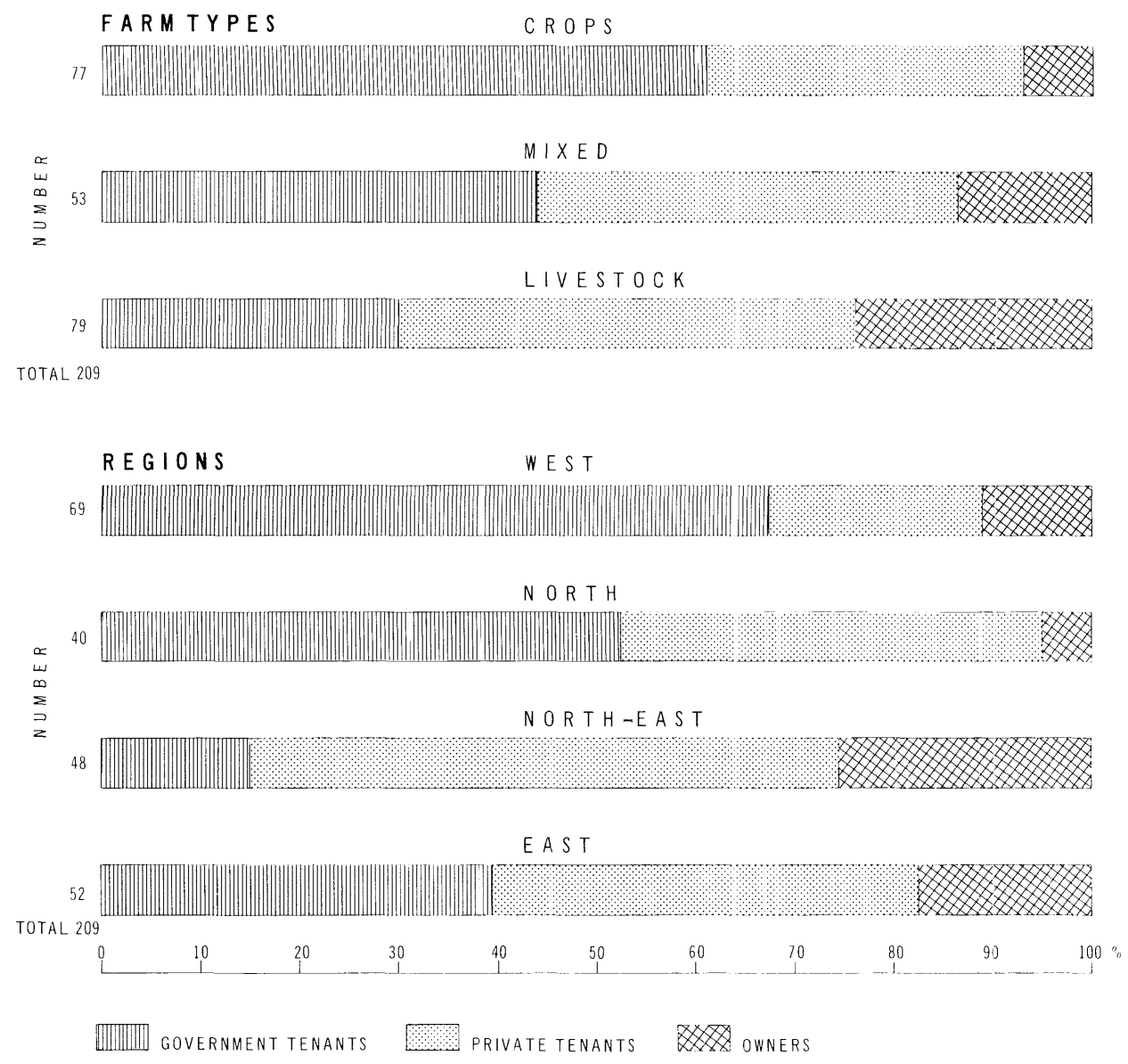

Figure 2 
Let us begin with the regional attribute. Thus we notice that in the Northeast the plots are on the average more extensive than in the other regions of the island and farmers who own them, proportionately more numerous. In the Northeast, farm production is very specialized and few crop growers are to be found. The great majority of the Sembawang, Yio Chu Kang and Punggol farm operators are poultry rearers, and 77 percent of the farmers of the northeast belong to the Teochew dialect group; in all the other regions put together the Teochews represent only 18 percent of all farmers. In other words, there exist marked regional differences. It remains difficult however, to isolate the "regional » element as the major factor of differentiation. For there exist equally strong correlations between the farm types and the various characteristics already correlated with the regions. The third element, the dialect group, also appears as a major predictor. In fact there is a definite inter-relation between region, dialect group and farm type (table 1). Thus the Northeast is not only predominantly a region of livestock rearing, but is also a region occupied mostly by Teochew. Furthermore, the Teochew, wherever they are found, appear to be mostly engaged in the rearing of livestock. When types of farms are considered it can be observed that very few of the crop cultivators own the land they farm (figure 2). However, a majority of these farmers who limit themselves to the cultivation of crops are found in areas such as Chua Chu Kang in the West, where most of the farm land belongs to the government.

These problems illustrate how difficult it can be to determine the predominant factor or predictor from simple statistical correlations. In fact there is a high degree of locational association between the farm type groups and the dialect groups. To illustrate this and following a standardized method, the degrees of locational association ${ }^{2}$ can be measured between the three variables, that is, the 8 regions, the 3 farm types and the 4 dialect groups.

These results indicate that dialect groups and types of farms are spatially associated to a high degree. This is particularly true of the Teochew who, as already pointed out, are mostly found in the Northeast where they comprise the great majority of farmers and where they are almost exclusively livestock rearers. The Hokkien are the predominant group numerically and they are also the most widely scattered. Like the Teochew, but to a lesser degree, they concentrate on livestock rearing, often combined with the cultivation of crops.

The Hakka and the Cantonese are predominantly crop growers; the reason the La measure does not give a clearer indication of their very strong spatial concentration is simply because the "regions" as defined are too broad. For in reality the Hakkas and particularly the Cantonese cultivators are concentrated in small areas which correspond to subdivisions of the

2 The locational association (La) is \& a measure of the degree to which certain types of institution or classes of population (such as ethnic or racial groups) are spatially associated ; ; see Gibbs, 1961, p. 247. The minimum La value is 0.0 and the maximum 100.0. 
Table 1

Dialect groups by region and farm type

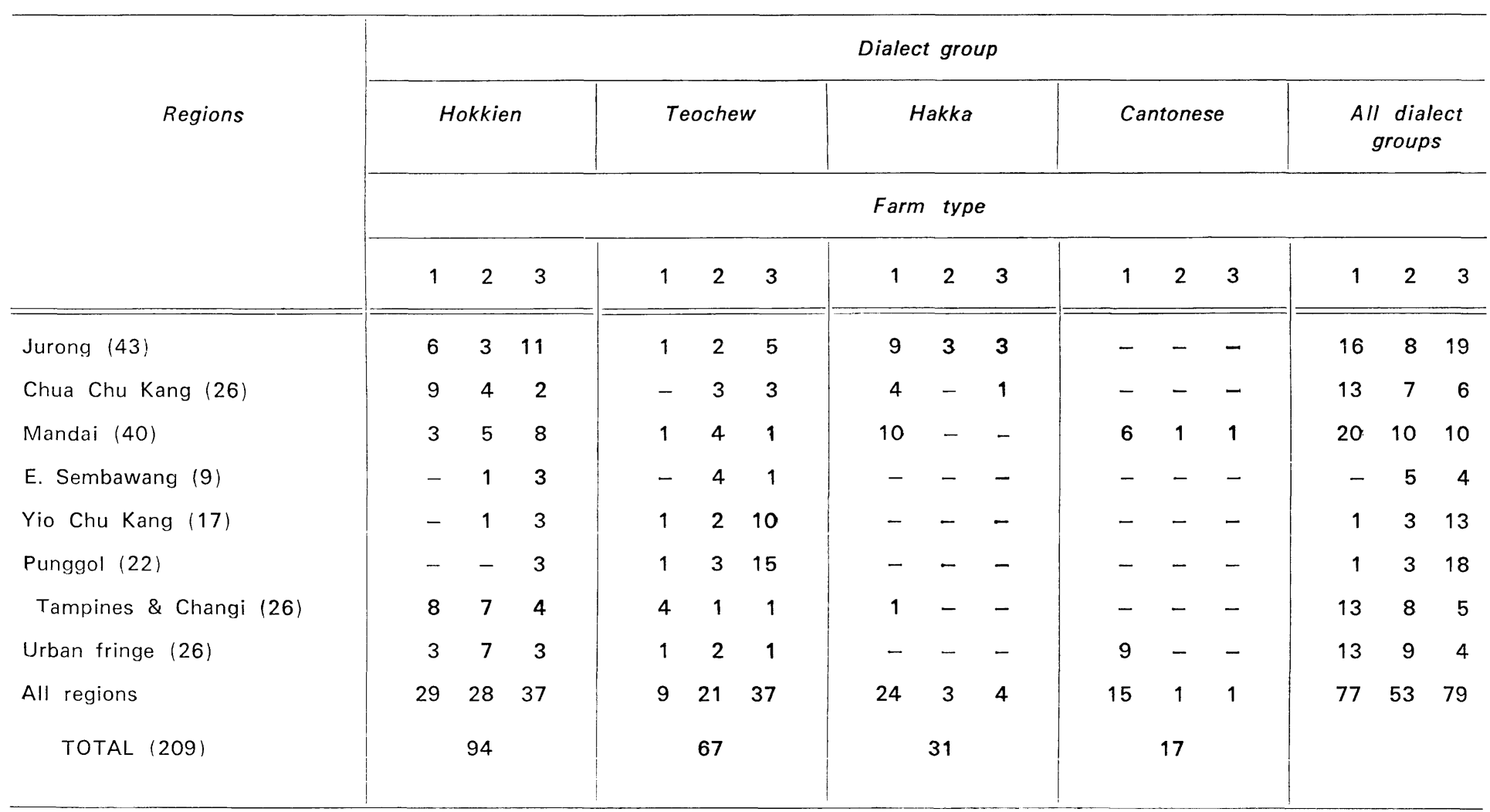

$1=$ Crops. (77) $2=$ Mixed. (53) $3=$ Livestock. (79) 
Table 2

Some degrees of locational association (La) between farm types and dialect groups

\begin{tabular}{l|c|c}
\hline \multicolumn{1}{c|}{ Farm type } & + Dialect group & $\begin{array}{c}\text { La (max } \\
100.0)^{*}\end{array}$ \\
\hline 1) Livestock farms & + Teochew & 84.0 \\
2) Mixed farms & + Hokkien & 86.7 \\
3) Mixed \& Livestock & + Teochew & 79.9 \\
4) Mixed \& Livestock & + Hokkien & 76.8 \\
5) Mixed \& Livestock & + Teochew, \\
6) Crop farms & Hokkien & 90.0 \\
7) Crop farms & + Hakka & 66.0 \\
& Cakka, & 76.7 \\
\hline
\end{tabular}

* If for example, all the representatives of one dialect group were found in given regions to the exclusion of all other groups and if, furthermore they were all crop farming (for example) then there would be a La of 100.0 for that given group and crop cultivation.

broader regions (figure 1). The Cantonese who appear as the least numerous are found essentially in two "pockets", the most important being the Potong Pasir area on the eastern fringe of the city and the other in the vicinity of Marsilling in the central north of the island. The Hakkas are also found in concentrated pockets in the Mandai Hills. A more marked concentration of Hakka cultivators can be seen in the western part of the island, among the low hills situated south of Chua Chu Kang village. Generally speaking the Cantonese appear to be the more communally concentrated of the two, with the Hakkas still occasionally found in dispersed localities.

In many respects the regions could almost be defined and distinguished by the predominant farm types and dialect groups. However, since the three major characteristics are so closely interrelated, further measures of association are necessary to investigate which of the three regional, professional and cultural groupings is more related to the major socio-economic characters of the farming population. In other words, which predictor has more value.

1 First attempts at finding a solution

As illustrated in figure 2, land tenure conditions vary substantially between the regions, the farm types and even the dialect groups. A simple table of correlation or a graphic illustration of these relations does not however tell whether the variations in land tenure conditions are more marked between the regions, between the farm types or between the dialect groups. Nor do tables and graphs measure the amplitude of these comparative variations. They do not always interpret clearly which of these three is most useful as 
a predictor of the land tenure condition of a given farmer - the region he lives in, the type of farm he operates or the dialect group he belongs to.

From simple tabulation and as illustrated in figure 2 it can be seen, for instance, that government tenants are few in the Northeast, particularly in Punggol, and numerous in the West particularly in Chua Chu Kang; it also appears that crop cultivators predominate amongst government tenants while the majority of land owners are livestock rearers; finally while most land owners are either Teochew or Hokkien, the Cantonese and the Hakka seem

Table 3

Farm types by dialect gorups and land tenure conditions

\begin{tabular}{|c|c|c|c|c|c|}
\hline \multirow{2}{*}{$\begin{array}{l}\text { Farm types } \\
\text { by Land tenure }\end{array}$} & \multicolumn{5}{|c|}{ Dialect group } \\
\hline & Hokkien & Teochew & Cantonese & Hakka & Total \\
\hline \multicolumn{6}{|l|}{ CROPS } \\
\hline Government tenant & 18 & 2 & 13 & 13 & 46 \\
\hline Private tenant & 8 & 6 & 1 & 9 & 24 \\
\hline Owner & 2 & 1 & 1 & 1 & 5 \\
\hline Not clear & 1 & - & - & 1 & 2 \\
\hline TOTAL & 29 & 9 & 15 & 24 & 77 \\
\hline \multicolumn{6}{|l|}{ LIVESTOCK } \\
\hline Government tenant & 12 & 8 & 1 & 2 & 23 \\
\hline Private tenant & 14 & 19 & - & 2 & 35 \\
\hline Owner & 8 & 10 & - & - & 18 \\
\hline Not clear & 3 & - & - & - & 3 \\
\hline TOTAL & 37 & 37 & 1 & 4 & 79 \\
\hline \multicolumn{6}{|l|}{ MIXED } \\
\hline Government tenant & 13 & 9 & - & 1 & 23 \\
\hline Private tenant & 10 & 9 & 1 & 2 & 22 \\
\hline Owner & 4 & 3 & - & - & 7 \\
\hline Not clear & 1 & - & - & - & 1 \\
\hline TOTAL & 28 & 21 & 1 & 3 & 53 \\
\hline \multicolumn{6}{|l|}{ TOTAL } \\
\hline Government tenant & 43 & 19 & 14 & 16 & 92 \\
\hline Private tenant & 32 & 34 & 2 & 13 & 81 \\
\hline Owner & 14 & 14 & 1 & 1 & 30 \\
\hline Not clear & 5 & - & - & 1 & 6 \\
\hline TOTAL & 94 & 67 & 17 & 31 & 209 \\
\hline
\end{tabular}


to have very little opportunity for land ownership. But which is the main determinant, the region, the farm type or the dialect group ?

A three variable correlation such as illustrated in table 3 refines the description somewhat by showing, for example, that the Teochew and Hokkien livestock rearers are the major land owners and that Hakka and Cantonese, whatever form of farming they practice, very rarely own any land. Further tabulation would indicate that the Teochew and Hokkien livestock rearers of Punggol and Yio Chu Kang often own their plot. But all these tabulations still do not provide a comparative measure of the degree of relationship that might exist between all three categories of occupancy status and all three farm types, all four dialect groups and all eight regions. An improvement in the knowledge of the degrees of relationship can be obtained by statistical measures.

\section{The solution employed}

One such measure, the gamma measure, has been used to improve statistically the evaluation of the comparative relationship between each of the three major predictors and a serie of socio-economic characteristics.

The use of various measures was considered but none was found perfectly adequate. The lambda measure, for example, assumes that there is "neither an underlying continuous variable, nor an intrinsic order to either of the attributes " (Zelditch, 1959 pp. 176-77). While nominal variables such as regions and tenancy status fulfil this condition, many attributes such as farm size or household size do not. But lambda's prohibitive weakness was that of not functioning when skewed variables such as dialect group (94 Hokkien, 17 Cantonese) were considered. The absence of fourfold tables eliminated the use of the phi coefficient or of the Yule's $\mathrm{Q}$ measure. The chi-square test, while being adaptable to contingency tables of any size and to ordinal and nominal variables did not prove versatile enough to account satisfactorily for the numerous frequencies of less than 5 (Maxwell, 1961, p. 38). Various solutions suggested to minimize this problem (ibid, p. 38 et. seq.) either required a large number of degrees of freedom or could not be applied uniformly to the three categories of predictor with their varying number of columns $(3,4$ and 8$)$. In other words, while some solutions could be found for certain tables, none was applicable uniformly to all of the 50 odd tables considered (see table 4).

The gamma measure did not present any problem of computation. But in theory it can only be used when " it is possible to assume that there is an intrinsic order underlying the characteristics measured " (Zelditch, op. cit., p. 180). While such an order could be assumed for all of the socioeconomic characters (see table 4) and even for the farm types, it could evidently not be the case for nominal variables such as dialect groups and regions.

Since the aim was not so much to measure the strength of association between the attributes as to evaluate the comparative relationship between the (interrelated) predictors and the socio-economic characters, we could of course have been satisfied with simply classifying the relationships as high, medium and low on the basis of substantive information and by studying the tables. However, for heuristic purposes it was decided to experiment 
with the gamma measure by adapting it; the predictors were consistently ordered from higher to lower according to the percentage distribution of the frequencies. This naturally provides the maximal measure and probably minimizes the possibilities of obtaining negative relationships but since it is applied uniformly it cannot affect substantially the proportions, which represent our basic interest. It is considered that this method, based on the proportional rather than the absolute statistics, offers a more refined, accurate and reliable measure of the regional, professional and cultural variations and relationships.

\section{The results}

In most cases the overall results, listed in table 4 , improve the identification of the major predictors. It appears evident, for example, that while there are strong regional variations in participation in Community Centre ${ }^{3}$ activities, hardly any differences are noticeable amongst the various professional and cultural groups. Also, the conditions of land tenure appear predominantly linked with regional trends. It is interesting to note that a strong relation that has been discovered earlier in the study between farm types and sizes had in fact to be traced back to the regions and the periods during which they were populated by farmers. In the older settled regions, because of less pressure on the land at the time, farmers were able to establish themselves on larger plots; in these same regions farmers also tend to rear livestock much more than in the others, possibly because livestock rearing requires more capital and the indispensable contacts, which can only be established with time (De Koninck, 1972 b). So in certain regions, particularly the longer settled ones, farmers have large plots and concentrate on livestock or mixed farming.

On the other hand, farm types, as might be expected, are better predictors of usage of PPD ${ }^{4}$ extension services and even household size and structure. Livestock rearing households appear to be larger and to have a more complex structure. It is probably for this reason that only 40 percent of them are fully farming against 52 percent for the crop growers and 60 percent for the mixed farmers. Large extended households having a dual economy therefore seem to be related more with livestock rearing, than with a given region such as Punggol or a given dialect group such as the Teochew. Ownership of a motor vehicle is also closely related to professional groupings which obviously present a better measure of material wealth, with 66 percent of the livestock rearers owning at least one motor vehicle, against 53 percent and 40 percent respectively for the mixed and the crop farmers.

3 The Community Centre have been developed by the P.A.P. government and are found throughout the island. In the rural areas, they are generally found in the villages (there are some cases of isolated Community Centre) and have become important meeting places, both for the villagers and for the visiting farmers. They play the role of cultural centers (plays, shows, television, etc.) and many government services are provided through them.

4 Primary Production Department. This government agency has, as one of its specific functions, to provide farmers with various extension services as well as with training, information, etc. 
Table 4

Comparative degrees (max. 1) of relationship as measured by gamma between the three main predictors and socio-economic characters

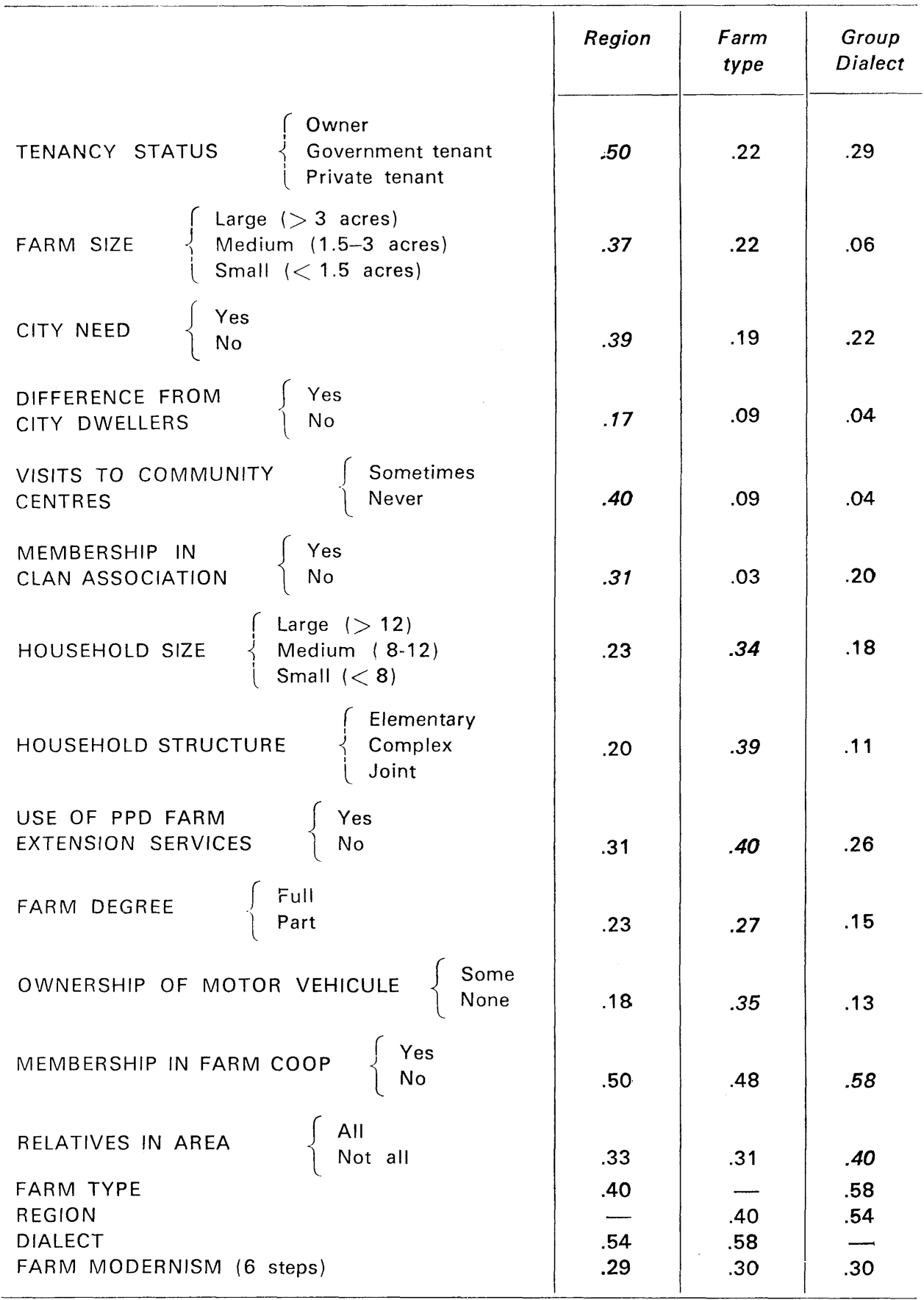


Although dialect groups are still more related to the presence of relatives in the neighbourhood ${ }^{5}$ and to the constitution of a few small farm cooperatives, the dominance is minimized by the fact that participation in Clan Associations ${ }^{6}$ varies more between the regions than between the dialect groups ; consequently the regions emerge as increasingly fundamental indicators of basic distinctions. Although material possessions, size and structure of household are more related to the type of farming enterprise there are indications that participation in a regional "class " or group is also important, not only because of the marked distinctions in participation in Community Centre activities but also because of the results on questions of city " need" and «difference ». To a question concerning how essential it is for them to go to the city, striking differences appear amongst the respondents of the various regions. Regional patterns also emerge when the farmers are asked if they feel different from city dwellers in their attitudes towards the Government over certain issues ${ }^{7}$. Among the 54 who state that they do feel different hardly any distinction is discernible between the various professional and ethnic groups. However farmers of the North and Northeast indicate more willingness to dissociate themselves from the city dwellers.

\section{$\checkmark$ Importance of regional characteristics}

As already pointed out, the three major predictors are closely interrelated; the adapted measure indicates that this is particularly noticeable when the dialect groups are related first to the farm types and to the regions (table 4). This implies that while the dialect group might have originally been a better indicator it has been replaced by more evolved forms of group identity $^{8}$ : forms of a regional nature and of a professional or farming class nature.

These findings suggest an answer to a question established earlier in the study concerning the role of villages and the apparent state of isolation and disorganization in which the farmers were left. There is in fact little evidence of any strong rural based organization (formal or informal) and the

5 A question was asked concerning the presence of relatives in the area. The respondents were grouped according to whether they said that all, or that only some of their relatives lived in the area. The majority of the respondents with all their relatives in the neighbourhood were the Teochews in the northeast which correspond to the older settled regions.

6 Percentage participation by dialect groups ranks in the following order: Cantonese 47, Hokkien 44, Hakka 42 and Teochew 30. By regions: Mandai 58, Punggol 46, Chua Chu Kang 42, Urban fringe 38, Yio Chu Kang 36, Sembawang 33, Jurong 33, Tampines and Changi 19.

7 The respondents were asked if they felt that activities of the Government such as laws passed, had any effect on their day to day life. After they had answered, they were then asked: "In what way if any would this be different for city dwellers ? "

8 In rural Hong Kong, the relationship between dialect groups, locations and farm types also appears to be very strong and according to Grant, 1960, p. 114, the dialect groups would offer the basic criteria of classification. 
farmers do appear "unorganized». However a large number of them have contacts, in one way or other with government agencies and the great majority do business with more than one trader and seem greatly to prefer their personal approach to business to any that could be imposed by an organization 9 . Their dealings with the outside, even if closely related to farm business are too frequent and too varied to be those of an exclusively pioneer community.

Most of the farmers can be said to be city oriented, but a large degree of variety exists since some go daily to town, others once a year (to pay taxes, land assessment, etc.). In fact, these differences testify to the existence of a dynamic evolution of distinct regional units since the " need of the city " varies substantially and basically between regions.

\section{Further analysis : a scale measure of modernism}

\section{Scale measure}

Knowledge of a farming household's "membership » in a given regional grouping within Singapore appears therefore an element fundamental to the description and analysis of its socio-economic characteristics. It remains however a crude measure and an attempt was made at classifying the respondents in a more sophisticated manner. For this, a Guttman scale of 5 items was constructed (table 5). The items included in the scale refer to what could be considered as various forms of input: the formal education received by the head of the household, two types of participation in extension programme ${ }^{10}$ of the PPD and possession of goods which can be tools of involvement in farming, of contacts with the exterior and of modernization of the farm.

The first and most common of the 5 attributes used in the scale is the ownership of a radio and the least common, that of a television and/or telephone, the assumption being that those that do not have any radio will not have any of the more sophisticated goods nor fulfil any of the intermediary requirements. In the same manner, those who do possess a television and/or a telephone can be expected to score positively on all the preceding steps ; the head of a household who has completed his primary education is expected to have attended talks and to listen regularly to the farm radio programmes and to own a radio.

Though not particularly high, the coefficients of scalability and of reproducibility are acceptable ${ }^{11}$ and this scale is used as a measure of farm

9 This pattern can be compared to the one described by Newell, 1962, pp. 202-03. In his conclusions on the study of a Chinese village of northeast Malaya, the author mentions "... the absence of traditional Chinese methods of organizing a village society. shown by the lack of clan and intra-village associations and their replacement by an elaborate framework of informal contacts. . . they are building a new society. "

10 The PPD extension programmes are different from their services.

11 By an acceptable Guttman scale is meant one for which the coefficient of reproducibility (CR) is .90 or higher (Philips, 1966, p. 193); and one for which the coefficient of scalability (CS) is .65 or higher (Menzel, 1953). 
Table 5

Scale of farm modernism

a) Scale contents

\begin{tabular}{|c|c|c|c|c|}
\hline & Content & $\begin{array}{c}\text { Decreasing } \\
\% \text { of cases } \\
\text { included }\end{array}$ & $\begin{array}{l}\text { No. of } \\
\text { cases } \\
\text { included }\end{array}$ & Errors \\
\hline 1. & Radio ownership & 71 & 149 & 20 \\
\hline 2. & Head listens to the weekly farm programme & 50 & 107 & 27 \\
\hline 3. & Head has attended talks given by the PPD staff & 41 & 87 & 24 \\
\hline 4. & $\begin{array}{l}\text { Head of household has completed } \\
\text { primary education }\end{array}$ & 24 & 49 & 21 \\
\hline 5. & Telephone and/or television ownership & 15 & 32 & 10 \\
\hline CS & $=.69 \quad \mathrm{CR}=.91 \quad \mathrm{~N}=209$ & & & \\
\hline
\end{tabular}

b) Scoring distribution

Farm modernity

High (steps $5+4$ )

Medium (steps $3+2$ )

Low (step $1+0$ )

TOTALS
Number of farmers

Percentage

$\left.\begin{array}{l}22 \\ 24\end{array}\right\}$

46

22

53

33

86

41

48

29
77

37

209

100

modernism, the least modern of the respondents scoring 0 as against 5 for the most modern. Admittedly, the scale measures attributes broader than those relevant only to farming but it is considered that it does measure a certain form of modernism which must have a strong influence on the state of the farm.

\section{The modern farmers}

When computed against the professional, ethnic and regional groupings, the farm modernism scores 12 of the respondents generally confirm previous

12 To make full use of the analytical power of the scale it would, in theory, be preferable to consider each of the 6 levels of farm modernism. The sample size of 209 does not however facilitate such detail analysis. In order to have categories large enough for analysis, the scale scores have been collapsed into three categories (table 5). 
findings but also provide further distinction (table 6). For although they point to the livestock rearers, to the Northeast and to the Teochew as being higher on farm modernity, they also single out as lower the mixed farmers, the Hokkien, and the Tampines and Changi areas in the East.

\section{Table 6}

Farm types, dialect groups and regions by percentage distribution of farm modernism score

\begin{tabular}{|c|c|c|c|c|c|}
\hline & & $\begin{array}{r}\text { High } \\
(\%)\end{array}$ & $\begin{array}{c}\text { Medium } \\
(\%)\end{array}$ & $\begin{array}{l}\text { Low } \\
(\%)\end{array}$ & $\begin{array}{c}\text { Total } \\
(\%)\end{array}$ \\
\hline Livestock & & 31 & 41 & 28 & 100 \\
\hline Crops & & 21 & 41 & 38 & 100 \\
\hline Mixed & & 10 & 42 & 48 & 100 \\
\hline Teochew & & 35 & 37 & 28 & 100 \\
\hline Hakka & & 24 & 33 & 43 & 100 \\
\hline Cantonese & & 18 & 47 & 35 & 100 \\
\hline Hokkien & & 12 & 46 & 42 & 100 \\
\hline Jurong & WEST & 13 & 47 & 40 & 100 \\
\hline Chua Chu Kang & VREO & 23 & 42 & 35 & 100 \\
\hline Mandai & NORTH & 13 & 47 & 40 & 100 \\
\hline E. Sembawang & & 13 & 62 & 25 & 100 \\
\hline Yio Chu Kang & NORTHEAST & 37 & 43 & 20 & 100 \\
\hline Punggol & & 50 & 27 & 23 & 100 \\
\hline Tampines \& Changi & EAST & 12 & 38 & 50 & 100 \\
\hline Urban Fringe & ו ו & 24 & 28 & 48 & 100 \\
\hline TOTAL & & 22 & 41 & 37 & \\
\hline
\end{tabular}

The scoring clearly indicates coordinates of the farmers most likely to be modern and points to the least modern type of farmers, but their regional and ethnic distribution is not so clear cut. The adapted measure does not help very much since the degrees of relationship are all equal or nearly so (table 4). A close examination of three variable tables confirms that the livestock rearers, particularly the Teochew of Punggol and the Northeast as the most modern, and the mixed farmers particularly the Hokkien of TampinesChangi as the least. But since it remains unclear which of the three groupings is the major predictor of farm modernism it appears impractical to try and "identify" intermediate categories of farmers. But the scale illustrates clearly an important point : the higher level of modernism of the crop culti- 
vators compared to that of the mixed farmers. In other words, even though the mixed farms correspond to larger enterprises, they are not necessarily more modern. This nuance is particularly important if only the mixed farms are considered or if all farms without distinction of types are classified in accordance with modernism scores. Nevertheless, when each farm type is subdivided in broad capital input categories, the relationship between size and modernism remains meaningful even if it follows a curvilinear pattern (figure 3 ).

That mixed farms appear markedly less modern than the more specialized livestock or crop farms might be an indication of the increasing success and appeal of product specialization in farming Singapore. Mixed farming is more traditional, tends to be more self-contained and for that reason less susceptible to modernization and less likely to risk specialization. Mixed farmers, though rearing livestock, make less use of the PPD veterinary services than do the "pure » livestock rearers and, on the other hand, make much less use of inorganic fertilizers than do the "pure » crop cultivators ${ }^{13}$.

\section{Involvement}

An additional important point illustrated by the scale is that the degree to which a household is farming does not seem to have any relevance to its farm modernity. It was discovered earlier in the study, that surprisingly small differences existed in terms of capital and labour input between the full farming and the part farming cases. The assumption that total involvement varies little between a full and a part farm is further supported by the scoring of the two categories on the modernism scale. When the strength of

Table 7

Farm degree and modernism

\begin{tabular}{lcccr}
\hline Degree & \multicolumn{4}{c}{ Modernism } \\
& High & Medium & Low & Total \\
\hline Full farming household & 21 & 47 & 35 & 103 \\
Part farming household & 25 & 39 & 42 & 106 \\
$\quad$ TOTAL & 46 & 86 & 77 & 209
\end{tabular}

13 That this might be related to the presence on many mixed farms of sufficient quantities of natural fertilizers does not affect the argument. The point remains : mixed farms make less use of modern farm amenities. There is also the possibility that mixed farmers, devoting less surface area to crop cultivation, cannot make use of chemical fertilizers because these require more fallow time and therefore the use of more land. This however is very unlikely since the average mixed farm is larger. It should also be remembered here that the average mixed farm relies on more fixed and running capital then does the average crop farm. 


\section{FARM TYPES BY CAPITAL INPUT AND PERCENTAGE OF MODERNISM CATEGORY}
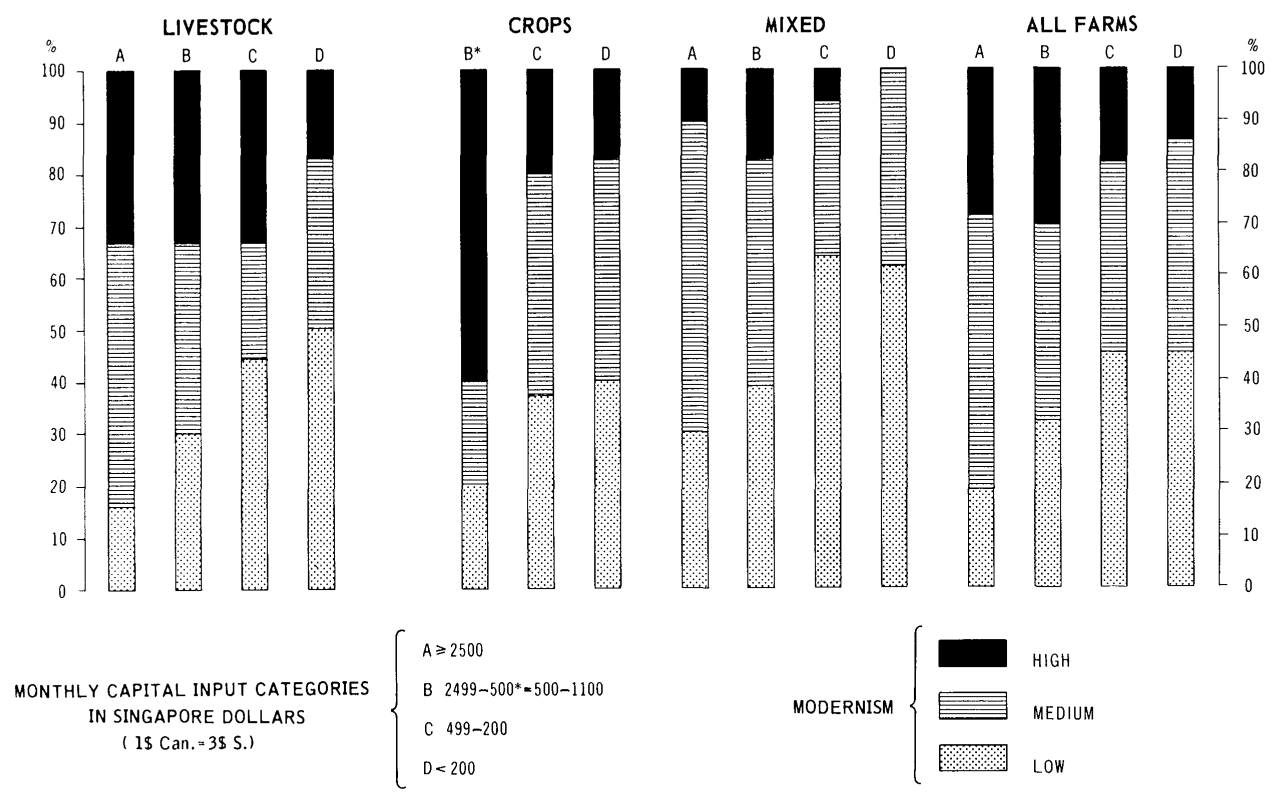

Figure 3

association is measured between all six steps of the scale and the farm degree attributes, the gamma measure reads $.009^{14}$ (table 8). Admittedly, the modernism scale does not measure farm involvement only, since it could also be said to give a certain assessment of material success, but it remains rather significant that, even less than labour and capital involvement (De Koninck, 1972 b), it fails to distinguish the full farms from the part farms.

However other indicators of involvement show stronger relations. By measuring the strength of association between various possible indicators and the levels of farm modernism it is possible to rank them according to their importance.

The strength of the associations between the use and knowledge of government services and farm modernity are particularly meaningful when compared with the ones existing with other possible agents such as city visits or Clan Associations. Direct contact with the city and off-farm employment of household members (part farms) do not appear to operate as agents of modernization and governiment services and amenities are obviously much more influential.

14 This refers to the original gamma measure of association as applicable to ordinal variables, and which extends from -1 to 1 , (Zelditch, p. 181). For the computation of the strength of association between various attributes such as farm degree and farm modernism, all six scores were used. 
Table 8

Rank order of association between possible indicators and agents of involvement and farm modernism (as measured by gamma)

Indicators and

agents
Association with

level of farm

modernism

Use of PPD extension services

Knowledge about assistance seeking

Visits to Community Centres

Participation in farm trade

City visits

Farm degree

\section{Conclusion}

Although further computations were carried out with other variables the results continued to support the basic findings which, along with the problems met and the methods used to solve them, can be summarized in the following terms.

In the results yielded by the analysis of survey data, three dominant variables emerged: the dialect group, the type of farm, the region. Attempts were then made to obtain a comparative measure of the degrees of relationships that might exist between each of the main predictors and other variables. The identification of the predominant attribute encountered various problems. First of all, the cultural (dialect and professional type of farm) show a high degree of locational association. The resultant close interrelation between the three variables makes it difficult to isolate the predominant one. Also, while the dominant variables were all nominal, many of the attributes (such as farm size) they were to be comparatively correlated with were ordinal. This limited the fields of possible measures of correlation. The large numbers of frequencies inferior to 5 limited the use of the chi-square test. Finally an adapted version of the gamma measure proved very efficient in evaluating the comparative discriminating habilities of the three main predictors.

Furthermore this methodological result was heightened by the fundamental finding it pointed to. While the dialect group probably had been the original form of group identity, it was now replaced by more local forms, forms more specific to Singapore, the professional group and mostly the regional attribute. In other words, among a Chinese community of the Nanyang, presumably in Singapore one of those most susceptible to retain strong 
ties with its cultural heritage ${ }^{15}$, Singaporean attributes and even regional Singaporean attributes appear to be the most reliable socio-economic indicator.

This essential statement was further refined by the use of a Guttman scale which served to measure the modernism of the farming households. According to scorings in the scale while livestock keepers are obviously the most modern ones, crop growers appeared more modern than mixed farmers ; and what is even more important, the farms of the part farming households appeared just as modern as those of the households whose livelihood depends exclusively on farming, a characteristic of great importance in the increasingly planned Singapore context (De Koninck, 1972 a).

\section{REFERENCES}

DE KONINCK, Rodolphe (1970), Chinese Farmers of Singapore: a study in social geography. Unpublished PhD thesis presented at the University of Singapore. 331 pages.

DE KONINCK, Rodolphe (1972 a). Aspects of Rural Resettlement in Singapore. To appear in the Proceedings of the 22nd International Geography Congress, Montréal.

DE KONINCK, Rodolphe (1972 b), Cultivateurs chinois de Singapour : population, organisation et comportement socio-économique. To appear in Travaux et Documents, Centre d'Études de Geographie Tropicale de Bordeaux, no 5.

GIBBS, J.P. éd. (1961), Urban Research Methods. New York, Van Nostrand. 625 pages.

GRANT, C.J. (1960), The Soils and Agriculture of Hong Kong. Hong Kong, Government Printer. 154 pages.

MAXWELL, A.E. (1961), Analysing Qualitative Data. London, Methuen. 163 pages.

MENZEL, Herbert (1953), A New Coefficient for Scalogram Analysis. Public Opinion Quarterly. 17 : $260-280$

NEVILLE, Warwick (1966), Singapore: Ethnic Diversity and its Implications. Annals of the Association of American Geographers, 56 (2): 236-253.

NEWELL, W.H. (1962), Treacherous River: A Study of Rural Chinese in North Malaya. Kuala Lumpur, University of Malaya Press. 233 pages.

PHILIPPS, B.S. (1966), Social Research. Strategy and Tactics. New York, MacMillan. 336 pages.

WONG, Poh Poh (1969). The Surface Configuration of Singapore Island: a quantitative description. Journal of Tropical Geography, $29: 64-74$.

ZELDITCH. M. (1959), A Basic Course in Sociological Statistics. New York, Holt Rinehart and Winston. 370 pages.

\section{ABSTRACT \\ Measuring the cultural evolution and the modernism of Chinese farmers of Singapore : an experiment \\ in the use of the gamma measure and of the Guttman scale}

In the analysis of data concerning the behavior of Chinese farmers and gathered through a sample survey of 209 households, three dominant variables kept recurring, namely the dialect group (Hokkien, Teochew, Hakka, Cantonese), the type of farm (livestock, crops, mixed), and the regional unit (8). An attempt was then made to obtain a comparative measure of the degrees of relationship that might exist between each of these dominant attributes and other variables. However the existence of a high degree of locational association between dialect groups and farm types made it particularly difficult to draw out a discriminatory measure. Furthermore, reliance on various measures of correlation was also hindered by the presence of nominal and ordinal variables, by the large number of frequencies inferior to 5 , which limits the use of chi-square, etc. Finally, an

15 It might be useful to point out at this stage that half of the heads of these farming households were born in China. 
adapted version of the gamma measure made it possible to distinguish comparative relations between the 3 major attributes and other socio economic characteristics.

This methodological result is particularly interesting for it points to a fundamental conclusion. While in the past the dialect group had probably been the original form of group identity, it was now being succeeded by more local forms, forms more specific to Singapore, the professionnal group and mostly the belonging to a given region. In other words, in a Chinese community of the Nanyang, presumably in Singapore one of the most susceptible to retain strong ties with its cultural heritage, Singaporean attributes and even regional Singaporean attributes appear to be the most reliable socio-economic indicator.

This essential statement is further refined by the use of a Guttman scale which serves to measure the modernism of the farming households. According to scorings on the scale, as might be expected, livestock keepers appear to be the most modern farmers ; however crop growers seem to be more modern than the mixed farmers. But what is even more important in the increasingly planned Singapore context, the farms of the part farming households seem to be just as modern as those of the households whose livelihood depends exclusively on farming.

\section{RÉSUMÉ}

\section{Mesure de l'évolution culturelle et du modernisme des agriculteurs chinois de Singapour: expérimentation de l'utilisation de la mesure gamma et de l'échelle de Guttman}

Au cours d'une étude portant sur la population des agriculteurs chinois de Singapour, une enquête par échantillonnage fut effectuée auprès de 209 foyers d'agriculteurs. À l'analyse du comportement de cette population, trois attributs se dégagèrent, à savoir l'appartenance à un groupe dialectal (Hokkien, Téochiou, Hakka, Cantonais), le type de ferme (élevage, cultures, exploitation mixte) et l'appartenance à l'une des 8 unités régionales. Il était donc nécessaire d'obtenir une mesure comparative des degrés de relation pouvant exister entre ces attributs dominants et d'autres variables. Cependant, l'utilisation d'une mesure discriminatoire s'avéra d'autant plus complexe que les 3 principaux attributs sont étroitement reliés, ce qui est illustré par le haut degré d'association spatiale entr'e groupe dialectal et type de ferme. De plus, l'utilisation de diverses mesures de corrélation était rendue difficile par la présence de variables nominales et ordinales, par le grand nombre de fréquences inférieures à 5 , ce qui limite la valeur du chi2, etc. Finalement une version adaptée de la mesure gamma a permis de dégager des degrés comparatifs de relation entre les 3 principaux attributs et les autres caractéristiques socio-économiques.

Ce résultat méthodologique a d'autant plus de valeur qu'il a permis de dégager une conclusion fondamentale. Alors que, par le passé, le groupe dialectal fut probablement la forme originale d'identité de groupe, il est aujourd'hui supplanté par des formes plus locales et plus spécifiques à Singapour, à savoir le groupe professionnel et surtout la région. En d'autres mots, au sein d'une communauté Chinoise du Nanyang, présumément à Singapour l'une des plus susceptibles de conserver des traces profondes de son héritage culturel, des attributs Singapouriens et même des attributs relevant de régions Singapouriennes semblent représenter le meilleur indicateur socio-économique.

Cette distinction essentielle est même affinée par le recours à une échelle de Guttman servant à mesurer le modernisme des foyers d'agriculteurs. D'après les résultats, alors que les éleveurs semblent de toute évidence les plus modernes, les maraîchers seraient plus modernes que ceux qui combinent cultures et élevage. Mais ce qui est encore plus important dans le "contexte» de plus en plus planifié de Singapour, c'est que les fermes des foyers partiellement agricoles semblent aussi modernes que celles des foyers vivant exclusivement de l'agriculture. 